\title{
DISCURSIVIDADES SOBRE APRENDER/APRENDIZAGEM NA PRODUÇÃO ACADÊMICA DA ÁREA DE ENSINO: OPERANDO COM UM ARQUIVO
}

Bruna Zanini Fiorin ${ }^{1}$

Angelica Vier Munhoz ${ }^{2}$

\begin{abstract}
Resumo: $\mathrm{O}$ artigo, que aqui se apresenta, deriva de uma investigaçáo, realizada junto ao Grupo de Pesquisa Currículo, Espaço, Movimento (CEM), existente desde 2013, com apoio do CNPq e da FAPERGS e vinculado ao Programa de Pós-Graduação em Ensino da Universidade do Vale do Taquari - Univates. $\mathrm{O}$ objetivo da investigação consistiu em tentar compreender de que modo o aprender/aprendizagem vem sendo engendrado nas discursividades pedagógicas das teses de doutorado, da área de ensino, no período de 2010 - 2019. Partindo da perspectiva arquivística de Michel Foucault (2015), buscou-se rastrear no Portal de teses da Capes, as produçóes acadêmicas que tomaram a noção de aprender/aprendizagem como objeto de estudo. Das 18 teses, oriundas desse rastreamento, foi possível perceber que a área de Ensino ainda traz fortemente pesquisas e pesquisadores, oriundos do campo das Ciências Exatas. Como em todo extrato enunciativo há sempre um lugar de enunciação, um lugar daquele que fala, as discursividades dos pesquisadores investigados carregam consigo o seu lugar de formação e, consequentemente, um determinado modo de ver o campo educacional, assim como, as resultantes conceituaçóes e teorizaçóes.
\end{abstract}

Palavras-chaves: arquivo; teses; ensino; aprender/aprendizagem.

\section{DISCURSIVITIES ABOUT LEARNING IN ACADEMIC PRODUCTION IN THE TEACHING AREA: WORKING WITH AN ARCHIVE}

\begin{abstract}
This paper has derived from an investigation carried out in the Curriculum, Space, Movement Research Group (CEM), which has existed since 2013, supported by CNPq and FAPERGS, and linked to the Graduate Program in Teaching of Vale do Taquari University - Univates. The aim of the investigation was to understand how learning was presented in pedagogical discursivities of
\end{abstract}

1 Graduanda de Psicologia; Bolsista de Iniciação científica PIBIC/CNPq - Grupo de Pesquisa Currículo, Espaço, Movimento (CEM/Univates).

2 Docente do Centro de Ciências Humanas e Sociais e do Programa de Pós-Graduação em EnsinoUniversidade do Vale do Taquari - Univates; Doutora em Educação pela UFRGS. 
doctoral dissertations in the teaching area, from 2010 to 2019. From the archive perspective of Michel Foucault (2015), there was an attempt to find out academic productions that took the notion of learning as their object of study, by means of a search in Capes dissertation portal. In the 18 dissertations found, it was possible to perceive the strong presence of research and researchers from the field of Exact Sciences in the teaching area. As in any enunciation excerpt, there is always a place of enunciation, the place of the one who speaks; the discursivities of the investigated researchers bring up their place of education and, consequently, a certain way of regarding the educational field, as well as the resulting conceptualizations and theorizations.

Keywords: archive; dissertations; teaching; learning.

\section{Introduçáo}

O presente artigo deriva de uma investigaçáo, realizada junto ao Grupo de Pesquisa Currículo, Espaço, Movimento (CEM), existente desde 2013, com apoio do CNPq e da FAPERGS e vinculado ao Programa de Pós-Graduação em Ensino da Universidade do Vale do Taquari - Univates. A partir de autores da Filosofia da Diferença, tais como Deleuze e Guattari, Foucault, Nietzsche, entre outros, o referido Grupo de Pesquisa tem por objetivo investigar os processos de ensinar e aprender, produzidos por práticas educativas e artísticas, em espaços escolares e não escolares. Para tanto, toma como campo empírico quatro espaços náo escolares espaços de arte - e dois espaços escolares. Interessa, portanto, para o Grupo CEM, aproximar-se intensivamente das noçôes de ensino e de aprendizagem que permeiam os currículos de espaços escolares e não escolares, assim como pensar tais processos.

É em meio ao curso de tais processos que a investigaçáo, aqui relatada, tomou como mote olhar para a noção de aprendizagem. Isso porque acredita-se que tal noção é um disparador importante para pensar e compreender os processos educacionais, e, sobretudo para a produção de práticas pedagógicas. Dessa maneira, o objetivo da investigaçáo consistiu em buscar compreender de que modo o aprender/aprendizagem vem sendo engendrado nas discursividades pedagógicas das teses de doutorado, da área de ensino, no período de 2010 - 2019 (últimos nove anos). Para tal feito, operou-se com a noção de arquivo de Michel Foucault (2015) como procedimento analítico de investigação.

\section{Sobre o aprender e a aprendizagem}

Ao longo da história, inúmeras teorizaçóes, abordagens e perspectivas teóricometodológicas acerca da noção de aprendizagem, foram constituindo formaçôes discursivas que perpassaram e continuam perpassando o campo da educação. Podemos situar uma matriz platônica da aprendizagem no pensamento educacional e pedagógico, a qual atrela o aprender a um pensamento representacional e a práticas de recognição. Este modelo da representaçáo ou da recogniçáo tem como função principal afirmar que conhecer é reconhecer e este reconhecimento exige um uso congruente das faculdades, no qual, cada faculdade transmite à outra uma identidade do objeto a ser conhecido ou reconhecido. Dessa maneira, através da recognição, o pensamento estabelece com o mundo uma relação cujo objetivo 
principal é o reconhecimento, a contemplaçáo. Mas, se a recogniçáo é uma das ocupaçóes do pensamento, certamente não é a sua principal tarefa. Contudo, embora estejamos distanciados da visão de Platão, tal concepção representacional ainda parece fazer eco nos discursos contemporâneos sobre aprendizagem, ressoando em práticas pedagógicas cotidianas fundadas na recogniçáo.

Mais recentemente, a Psicologia Educacional tentou explicar os processos de aprender vinculados ao par ensino-aprendizagem, relacionando, de forma indissolúvel, estas duas açóes - o ensinar e o aprender. Muitas teorias de aprendizagem do século vinte continuam operando com essa 'dobradinha', de modo que se acredita que "só se aprende aquilo que é ensinado ou náo se pode aprender sem que alguém ensine" (GALLO, 2012, p.02). Podemos compreender que essa relaçáo entre o aprender e o ensinar, conectado pela via da recognição, deram uma certa forma para a escola: a de que alguém - o professor - ensina tudo a todos os seus alunos, que todos aprendem a mesma coisa no mesmo tempo, que o que é ensinado pelo professor é um saber e, portanto, o que o aluno deve prestar contas, por meio de avaliaçóes, é aquilo que foi ensinado e, consequentemente, aprendido.

É fato que, a partir dos meados dos anos 90, teorizaçôes que se convencionaram a nomear pós-críticas, buscaram dar novas conceituações à noção de aprender, tomando como pilares teóricos as ideias de Michel Foucault (2001, 2004), Gilles Deleuze (2003, 2006), Friedrich Nietzsche (2004), Baruch Spinoza (2007) - que embora não fossem teóricos da educação, em alguma medida nos ajudaram a problematizar ou colocar em suspensão tal noção. Sobretudo Deleuze, em duas de suas obras - Diferença e repetição (2003) e Proust e os signos (2006), rompe com pensamentos clássicos acerca da aprendizagem, relacionando a ideia de aprender (e não aprendizagem), ao movimento do pensar. Ou seja, o aprender náo se agencia ao ensinar ou a o saber, mas ao pensar. Com efeito, o pensar, para Deleuze (2003), não é recognição, mas é da ordem do ainda não pensado, de modo que o que força o pensamento a pensar é o encontro com os signos. Assim, se pensar é o momento em que o signo de algo estranho ao pensamento entra no campo de percepçáo, o aprender é o momento de decifração e interpretação desse signo, ou nas palavras de Deleuze (2006, p.4), "aprender diz respeito essencialmente aos signos". Nessa perspectiva, aprender não é reproduzir ou repetir um saber, mas inaugurar; inventar o ainda não existente.

Vemos aqui uma diferença de sentido entre o aprender de Deleuze e a aprendizagem, a partir de diferentes autores, advindos da Psicologia Educacional. Em relação à noção de aprendizagem, ainda há de se considerar que o mercado se apropriou de tal noçáo tornando-a carregada de ideologias cognitivistas, psicológicas e individualistas, tal como afirma Larrosa (2018). Segundo o autor (2018), a palavra aprendizagem está carregada de objetivos com vistas a resultados, à motivaçáo, à diversão e responde a necessidades e a satisfaçóes imediatas. Nesta perspectiva de aprendizagem, não se trata "de aprender algo, mas do assim chamado aprender a aprender”. E em relação ao aprender a aprender, Larrosa afirma: 
Não precisa ser muito perspicaz para perceber a relação do aprender a aprender com a produçáo de um profissional (de um sujeito) flexível, multiuso, multifuncional, adaptável, intercambiável e, dessa maneira completamente descaracterizado, esvaziado, dessubjetivado, supérfluo, condenado à obsolescência e, por assim dizer, a uma aprendizagem sem fim, à reciclagem permanente. (LAROSSA, 2018, p. 56).

Também Masschelein e Simons (2018), se contrapóem a ideia de uma aprendizagem que pode ocorrer em qualquer momento e em qualquer lugar ou que qualquer lugar é um ambiente de aprendizagem. Para os autores, dizer que "a escola é para a aprendizagem não diz nada sobre o que faz da escola uma escola" (MASSCHELEIN; SIMONS, 2018, p. 91). Nessa perspectiva, transformar a escola num ambiente de aprendizagem, muitas vezes, diz respeito, mais a torná-lo um espaço estimulante, variado, dinâmico, flexível e menos a fazer dela um espaço de estudo e de um aprender no sentido deleuzeano do pensar.

Assim, de Platão, às abordagens comportamentalistas, humanistas, cognitivistas; dos pensadores com grande projeção no cenário educacional a partir da década de 80, como Jean Piaget, Lev Vygotsky, David Ausubel às ideias dos autores Pós-estruturalistas já citados, há um amplo repertório de discursividades, cujo fim é buscar compreender os processos de aprendizagem/aprender. Em meio a tantas variações de perspectivas, poderíamos nos perguntar: Como estamos operando com as noçóes de aprender/aprendizagem na sala de aula? O que está sendo produzido nas pesquisas acadêmicas sobre o aprender/aprendizagem?

\section{Das inquietaçóes e achados da investigaçáo}

Diante das inquietaçóes que cercearam a investigação, partiu-se da seguinte questão: de que modo o aprender/aprendizagem vem sendo engendrado nos discursos pedagógicos das pesquisas acadêmicas da área de Ensino (teses de doutorado), no período de 2010-2019? Cabe destacar que a Área de Ensino é constituída pela Portaria CAPES no 83/2011, inserindo-se na grande Área Multidisciplinar e nucleando a antiga Área de Ensino de Ciências e Matemática. No Portal da Capes, as primeiras teses da área aparecem a partir de 2010, o que explicou o ano de início dessa investigaçáo. A escolha pela Área de Ensino se justifica pois, como já mencionado, o Grupo de Pesquisa Currículo, Espaço, Movimento, o qual essa investigação está vinculada, integra o Pós-Graduação em Ensino, da Universidade do Vale do Taquari - Univates.

Para a realização da investigação, buscou-se a aproximação com a noção de arquivo de Michel Foucault (2008). O arquivo para Foucault é o "conjunto de discursos efetivamente pronunciados" (FOUCAULT, 2000, p. 149), ou seja, aquilo que pode ser enunciado, que pode ser dito (FOUCAULT, 2008). É no arquivo que os enunciados se materializam se dispersam, se acumulam, se opóem, se conservam e se modificam. Nessa perspectiva, o arquivo se constitui pelo conjunto de discursos e para Foucault (2001), um discurso não é apenas um conjunto de signos, de significantes que se referem a determinados conteúdos com algum significado 
oculto e intençóes dissimuladas, mas uma rede de signos que se conectam a outras tantas redes de outros discursos. Assim, o arquivo é o que rege o aparecimento de novos enunciados, porém, "não há enunciado em geral, enunciado livre, neutro e independente; mas sempre um enunciado fazendo parte de uma série ou de um conjunto, desempenhando um papel no meio dos outros, neles se apoiando e deles se distinguindo" (FOUCAULT, 2008, p. 112). Ao constituirmos um determinado arquivo como objeto de análise, recortamos um problema, delimitamos as suas relaçôes, configuramos os procedimentos e categorias de análise. Contudo, operar com a noção de arquivo, também nos coloca em uma certa perspectivação, pois ao tomar o arquivo sob a ótica de Foucault, não estamos nos referindo a um depositário cuja tarefa é salvaguardar um conjunto de informaçóes referentes ao passado, mas a um arquivo vivo e aberto que se relaciona com o futuro, o que requer necessariamente a desmontagem e remontagem das matérias que nele habitam.

Partindo de tal perspectiva arquivística, inicialmente buscou-se rastrear, no Portal de teses da Capes, produçóes acadêmicas (teses de doutorado), entre o período de 2010 - 2019, da área de Ensino, que tomam a noção de aprender/ aprendizagem como objeto de estudo. Para uma primeira busca, utilizou-se os descritores "aprender" e "aprendizagem" e foram encontradas 44 teses. No segundo momento, cada uma dessas teses foi analisada, com foco em seus resumos e palavraschaves e das 44 teses disponíveis, 22 apresentavam as palavras "aprender" e/ou "aprendizagem" em um ou nos dois desses dois indicativos (resumo, palavras-chave e/ou PPG/linha). Das 22 teses, oriundas desta segunda seleção, 4 teses apresentaram temáticas que não correspondiam ao objetivo do presente trabalho, portanto foram descartadas do rastreamento inicial.

Feito isso, foi iniciado o processo de primeiro arquivamento das 18 teses restantes, a partir da tabulação das seguintes categorias: nome do doutorando, título da tese, área de formação inicial, universidade vinculada, programa e linha de pesquisa, ano da defesa. No quadro A, encontram-se apenas o título das teses, enumeradas de 1 a 18 . No Quadro B estão as demais informaçóes correspondentes ao número da tese.

Quadro A

\begin{tabular}{|c|c|}
\hline Título da tese & Número \\
\hline A Disseminação Dos Três Momentos Pedagógicos: Um Estudo Sobre Práticas Docentes Na \\
$\begin{array}{c}\text { Região } \\
\text { De Santa Maria/RS }\end{array}$ & 1 \\
\hline $\begin{array}{c}\text { A Articulação Das Culturas Humanísticas E Científicas Por Meio Do Estudo Histórico } \\
\text { Sociocultural Dos Trabalhos De James Prescott Joule: Contribuiçóes Para A Formaçáo De } \\
\text { Professores Universitários Em Uma Perspectiva Transformadora }\end{array}$ & 2 \\
\hline $\begin{array}{c}\text { Educaçáo Médica A Partir Da Perspectiva Humanística De Carl Rogers: Uma Vivência De } \\
\text { Sala De Aula }\end{array}$ & 3 \\
\hline (Co)Educar Em Rede De Conversação : Formação De Professores Em Educação A Distância & 4 \\
\hline
\end{tabular}




\begin{tabular}{|c|c|}
\hline Título da tese & Número \\
\hline $\begin{array}{c}\text { Redes De Conversação Como Possibilidade De Formaçáo Do Professor Tutor Virtual Na } \\
\text { Mediaçáo Pedagógica Da Educaçáo Profissional A Distância }\end{array}$ & 5 \\
\hline $\begin{array}{c}\text { A Mudança Paradigmática No Processo De Ensino-aprendizagem Na Disciplina De Patologia: } \\
\text { Contribuição Para A Educação Médica }\end{array}$ & 6 \\
\hline O Aprender Em Ambientes De Aprendizagem Configurando Uma Cultura Escolar & 7 \\
\hline $\begin{array}{l}\text { A Hermenêutica Filosófica No Horizonte Da Educaçáo Química: O Professor De Química } \\
\text { Como Tradutor-intérprete De Uma Tradição De Linguagem }\end{array}$ & 8 \\
\hline O Método Cognitivo-histórico E O Ensino De Física Mediado Por Epistemologias & 9 \\
\hline $\begin{array}{c}\text { Conversas Sobre A Gestáo Do Ensino Mediado Por Tecnologias Digitais: Controvérsias E } \\
\text { Desafios }\end{array}$ & 10 \\
\hline $\begin{array}{l}\text { Entre Sonhos E Realidades: A Auto-eco-formaçáo Interdisciplinar De Professores Em Ciências } \\
\qquad \text { Da Natureza }\end{array}$ & 11 \\
\hline $\begin{array}{c}\text { Nascimento E Evoluçáo Da Disciplina De Física No Ensino Secundário Brasileiro: Uma } \\
\text { Análise A Partir Da Teoria De David Layton }\end{array}$ & 12 \\
\hline $\begin{array}{l}\text { Seminário Integrado: As Faces Do Reconhecimento Do Outro Para Professores De Ciências } \\
\text { Participantes Do Cirandar }\end{array}$ & 13 \\
\hline Sistema De Numeração Decimal No Ciclo De Alfabetização: As Açôes Docentes & 14 \\
\hline $\begin{array}{c}\text { Cartografia De Redes De Conversação Entre Os Profissionais Da Educação Básica E Superior } \\
\text { Na Profissionalização Da Docência. }\end{array}$ & 15 \\
\hline $\begin{array}{l}\text { O Laboratório De Ensino E Prática Docente - Lepd Como Espaço De Cooperaçấo E } \\
\text { Formação Docente }\end{array}$ & 16 \\
\hline $\begin{array}{l}\text { A Rede De Conversação Em Uma Cultura Digital: Um Modo De Pensar, Agir e } \\
\text { Compreender O Ensino De Matemática Na Educaçáo Superior }\end{array}$ & 17 \\
\hline $\begin{array}{l}\text { Formação De Professores De Matemática A Partir Da Experiência De Alunos e Professores } \\
\qquad \text { Cegos }\end{array}$ & 18 \\
\hline
\end{tabular}

\section{Quadro B}

\begin{tabular}{|l|l|l|l|l|l|}
\hline $\mathbf{N}^{\circ}$ & Autor & $\begin{array}{l}\text { Formaçáo } \\
\text { Inicial }\end{array}$ & IES & PPG/Linha & $\begin{array}{l}\text { Ano da } \\
\text { defesa }\end{array}$ \\
\hline 1 & $\begin{array}{l}\text { Cristiane } \\
\text { Muenchen }\end{array}$ & $\begin{array}{l}\text { Física } \\
\text { Licenciatura }\end{array}$ & $\begin{array}{l}\text { Universidade } \\
\text { Federal de } \\
\text { Santa Catarina } \\
\text { (UFSC) }\end{array}$ & $\begin{array}{l}\text { Programa de pós-graduaçáo em } \\
\text { educação científica e tecnológica }\end{array}$ & 2010 \\
\hline 2 & $\begin{array}{l}\text { Wellington } \\
\text { Pereira De } \\
\text { Queirós }\end{array}$ & $\begin{array}{l}\text { Física } \\
\text { Licenciatura }\end{array}$ & $\begin{array}{l}\text { Universidade } \\
\text { Estadual } \\
\text { Paulista } \\
\text { (UNESP) }\end{array}$ & $\begin{array}{l}\text { Programa de pós-graduação } \\
\text { em educaçáo para a ciência } \\
\text { (Linha: Ensino de Ciências e } \\
\text { Matemática) }\end{array}$ & 2012 \\
\hline
\end{tabular}




\begin{tabular}{|c|c|c|c|c|c|}
\hline $\mathbf{N}^{\circ}$ & Autor & $\begin{array}{l}\text { Formaçáo } \\
\text { Inicial }\end{array}$ & IES & PPG/Linha & $\begin{array}{l}\text { Ano da } \\
\text { defesa }\end{array}$ \\
\hline 3 & $\begin{array}{l}\text { Hugo Cataud } \\
\text { Pacheco } \\
\text { Pereira }\end{array}$ & Medicina & $\begin{array}{l}\text { Universidade } \\
\text { Federal do Rio } \\
\text { Grande (FURG) }\end{array}$ & $\begin{array}{l}\text { Programa de Educação em } \\
\text { Ciências: Química da vida e } \\
\text { saúde (Linha: Processos de ensino } \\
\text { e aprendizagem na escola, na } \\
\text { universidade e no laboratório de } \\
\text { pesquisa) }\end{array}$ & 2013 \\
\hline 4 & $\begin{array}{l}\text { Berenice Vahl } \\
\text { Vaniel }\end{array}$ & $\begin{array}{l}\text { Física } \\
\text { Licenciatura }\end{array}$ & $\begin{array}{l}\text { Universidade } \\
\text { Federal do Rio } \\
\text { Grande (FURG) }\end{array}$ & $\begin{array}{l}\text { Programa de Educação em } \\
\text { Ciências: Química da vida e } \\
\text { saúde (Linha: As tecnologias } \\
\text { educativas no processo de } \\
\text { aprendizagem) }\end{array}$ & 2013 \\
\hline 5 & $\begin{array}{l}\text { Fernando } \\
\text { Augusto } \\
\text { Treptow Brod }\end{array}$ & $\begin{array}{l}\text { Tecnologia em } \\
\text { Processamento } \\
\text { de Dados }\end{array}$ & $\begin{array}{l}\text { Universidade } \\
\text { Federal do Rio } \\
\text { Grande (FURG) }\end{array}$ & $\begin{array}{l}\text { Programa de Educação em } \\
\text { ciências: Quìmica da vida e saúde } \\
\text { (Linha: As tecnologias educativas } \\
\text { no processo de aprendizagem) }\end{array}$ & 2014 \\
\hline 6 & $\begin{array}{l}\text { Obirajara } \\
\text { Rodrigues }\end{array}$ & $\begin{array}{l}\text { Med. } \\
\text { Veterinaria / } \\
\text { Medicina }\end{array}$ & $\begin{array}{l}\text { Universidade } \\
\text { Federal do Rio } \\
\text { Grande (FURG) }\end{array}$ & $\begin{array}{l}\text { Programa de Educaçáo em } \\
\text { Ciências: Quìmica da vida e } \\
\text { saúde (Linha: Processos de ensino } \\
\text { e aprendizagem na escola, na } \\
\text { universidade e no laboratório de } \\
\text { pesquisa) }\end{array}$ & 2014 \\
\hline 7 & $\begin{array}{l}\text { Vanda Leci } \\
\text { Bueno } \\
\text { Gauterio }\end{array}$ & $\begin{array}{l}\text { Matemática } \\
\text { Licenciatura / } \\
\text { Pedagogia }\end{array}$ & $\begin{array}{l}\text { Universidade } \\
\text { Federal do Rio } \\
\text { Grande (FURG) }\end{array}$ & $\begin{array}{l}\text { Programa de Educação em } \\
\text { Ciências: Quìmica da vida e } \\
\text { saúde (Linha: As tecnologias } \\
\text { educativas no processo de } \\
\text { aprendizagem) }\end{array}$ & 2014 \\
\hline 8 & $\begin{array}{l}\text { Robson } \\
\text { Simplicio De } \\
\text { Sousa }\end{array}$ & $\begin{array}{l}\text { Química } \\
\text { Licenciatura }\end{array}$ & $\begin{array}{l}\text { Universidade } \\
\text { Federal do Rio } \\
\text { Grande (FURG) }\end{array}$ & $\begin{array}{l}\text { Programa de Educação em } \\
\text { Ciências: Quìmica da vida e } \\
\text { saúde (Linha: Processos de ensino } \\
\text { e aprendizagem na escola, na } \\
\text { universidade e no laboratório de } \\
\text { pesquisa) }\end{array}$ & 2016 \\
\hline 9 & $\begin{array}{l}\text { Paola Jardim } \\
\text { Cauduro }\end{array}$ & $\begin{array}{l}\text { Física } \\
\text { Licenciatura } \\
\text { / Matemática } \\
\text { Lic. }\end{array}$ & $\begin{array}{l}\text { Universidade } \\
\text { Federal de Santa } \\
\text { Maria (UFSM) }\end{array}$ & $\begin{array}{l}\text { Programa de Educação em } \\
\text { Ciências: Quìmica da vida e } \\
\text { saúde (Linha: Processos de ensino } \\
\text { e aprendizagem na escola, na } \\
\text { universidade e no laboratório de } \\
\text { pesquisa }^{3}\end{array}$ & 2016 \\
\hline
\end{tabular}

3 O Programa de Pós-Graduação em Educação em Ciências: Química da vida e saúde funciona como um Programa de Pós-graduação interinstitucional, tendo como sede a Universidade Federal do Rio Grande do Sul (UFRGS) e como instituiçóes parceiras a Universidade Federal do Rio Grande (FURG) e a Universidade Federal de Santa Maria (UFSM). 


\begin{tabular}{|c|c|c|c|c|c|}
\hline $\mathbf{N}^{\circ}$ & Autor & $\begin{array}{l}\text { Formaçáo } \\
\text { Inicial }\end{array}$ & IES & PPG/Linha & $\begin{array}{l}\text { Ano da } \\
\text { defesa }\end{array}$ \\
\hline 10 & $\begin{array}{l}\text { Cesar Costa } \\
\text { Machado }\end{array}$ & $\begin{array}{l}\text { Engenharia } \\
\text { Elétrica / } \\
\text { Programa Esp. } \\
\text { Formação } \\
\text { Pedagógica de } \\
\text { Docentes }\end{array}$ & $\begin{array}{l}\text { Universidade } \\
\text { Federal do Rio } \\
\text { Grande (FURG) }\end{array}$ & $\begin{array}{l}\text { Programa de Educação em } \\
\text { Ciências: Quìmica da vida e } \\
\text { saúde (Linha: As tecnologias } \\
\text { educativas no processo de } \\
\text { aprendizagem) }\end{array}$ & 2017 \\
\hline 11 & $\begin{array}{l}\text { Rafaele } \\
\text { Rodrigues De } \\
\text { Araujo }\end{array}$ & $\begin{array}{l}\text { Física } \\
\text { Licenciatura }\end{array}$ & $\begin{array}{l}\text { Universidade } \\
\text { Federal do Rio } \\
\text { Grande (FURG) }\end{array}$ & $\begin{array}{l}\text { Programa de Educação em } \\
\text { Ciências: Quìmica da vida e } \\
\text { saúde (Linha: Processos de ensino } \\
\text { e aprendizagem na escola, na } \\
\text { universidade e no laboratório de } \\
\text { pesquisa) }\end{array}$ & 2017 \\
\hline 12 & $\begin{array}{l}\text { Cristiano Da } \\
\text { Silva Buss }\end{array}$ & $\begin{array}{l}\text { Física } \\
\text { Licenciatura }\end{array}$ & $\begin{array}{l}\text { Universidade } \\
\text { Federal do Rio } \\
\text { Grande (FURG) }\end{array}$ & $\begin{array}{l}\text { Programa de Educação em } \\
\text { Ciências: Quìmica da vida e } \\
\text { saúde (Linha: Processos de ensino } \\
\text { e aprendizagem na escola, na } \\
\text { universidade e no laboratório de } \\
\text { pesquisa) }\end{array}$ & 2017 \\
\hline 13 & $\begin{array}{l}\text { Marcia Von } \\
\text { Fruhauf Firme }\end{array}$ & $\begin{array}{l}\text { Ciências - hab } \\
\text { em química }\end{array}$ & $\begin{array}{l}\text { Universidade } \\
\text { Federal do Rio } \\
\text { Grande (FURG) }\end{array}$ & $\begin{array}{l}\text { Programa de Educação em } \\
\text { Ciências: Quìmica da vida e } \\
\text { saúde (Linha: Processos de ensino } \\
\text { e aprendizagem na escola, na } \\
\text { universidade e no laboratório de } \\
\text { pesquisa) }\end{array}$ & 2017 \\
\hline 14 & $\begin{array}{l}\text { Danielle } \\
\text { Cenci }\end{array}$ & $\begin{array}{l}\text { Matemática } \\
\text { Licenciatura }\end{array}$ & $\begin{array}{l}\text { Universidade } \\
\text { Federal do Rio } \\
\text { Grande (FURG) }\end{array}$ & $\begin{array}{l}\text { Programa de Educação em } \\
\text { Ciências: Quìmica da vida e } \\
\text { saúde (Linha: Processos de ensino } \\
\text { e aprendizagem na escola, na } \\
\text { universidade e no laboratório de } \\
\text { pesquisa }\end{array}$ & 2017 \\
\hline 15 & $\begin{array}{l}\text { Rejane } \\
\text { Conceicao } \\
\text { Silveira Da } \\
\text { Silva }\end{array}$ & $\begin{array}{l}\text { Engenharia } \\
\text { Civil / } \\
\text { Matemática } \\
\text { Licenciatura }\end{array}$ & $\begin{array}{l}\text { Universidade } \\
\text { Federal do Rio } \\
\text { Grande (FURG) }\end{array}$ & $\begin{array}{l}\text { Programa de Educação em } \\
\text { Ciências: Quìmica da vida e } \\
\text { saúde (Linha: As tecnologias } \\
\text { educativas no processo de } \\
\text { aprendizagem) }\end{array}$ & 2017 \\
\hline 16 & $\begin{array}{l}\text { Cristina Maria } \\
\text { Loyola Zardo }\end{array}$ & $\begin{array}{l}\text { Ciências } \\
\text { Biológicas } \\
\text { Licenciatura }\end{array}$ & $\begin{array}{l}\text { Universidade } \\
\text { Federal do Rio } \\
\text { Grande (FURG) }\end{array}$ & $\begin{array}{l}\text { Programa de Educaçáo em } \\
\text { ciências: Quìmica da vida e saúde } \\
\text { (Linha: As tecnologias educativas } \\
\text { no processo de aprendizagem) }\end{array}$ & 2017 \\
\hline 17 & $\begin{array}{l}\text { Daniel Da } \\
\text { Silva Silveira }\end{array}$ & $\begin{array}{l}\text { Matemática } \\
\text { Licenciatura }\end{array}$ & $\begin{array}{l}\text { Universidade } \\
\text { Federal do Rio } \\
\text { Grande (FURG) }\end{array}$ & $\begin{array}{l}\text { Programa de Educação em } \\
\text { Ciências: Quìmica da vida e } \\
\text { saúde (Linha: As tecnologias } \\
\text { educativas no processo de } \\
\text { aprendizagem) }\end{array}$ & 2017 \\
\hline
\end{tabular}




\begin{tabular}{|l|l|l|l|l|l|}
\hline $\mathbf{N}^{\circ}$ & Autor & $\begin{array}{l}\text { Formaçáo } \\
\text { Inicial }\end{array}$ & IES & PPG/Linha & $\begin{array}{l}\text { Ano da } \\
\text { defesa }\end{array}$ \\
\hline 18 & $\begin{array}{l}\text { Daner Silva } \\
\text { Martins }\end{array}$ & $\begin{array}{l}\text { Matemática } \\
\text { Licenciatura }\end{array}$ & $\begin{array}{l}\text { Universidade } \\
\text { Federal do Rio } \\
\text { Grande (FURG) }\end{array}$ & $\begin{array}{l}\text { Programa de Educação em } \\
\text { Ciências: Quìmica da vida e } \\
\text { saúde (Linha: Processos de ensino } \\
\text { eaprendizagem na escola, na } \\
\text { universidade e no laboratório de } \\
\text { pesquisa) }\end{array}$ & 2019 \\
\hline
\end{tabular}

Após esse arquivamento inicial, cada uma das 18 teses foi analisada em relaçáo ao aparecimento das noçóes de aprender e/ou aprendizagem. Assim, uma nova categorização foi realizada em relação ao número de vezes que as palavras "aprender" e/ou "aprendizagem" apareciam em cada tese, conforme quadro que segue.

Quadro C

\begin{tabular}{|c|c|c|}
\hline Número da tese & Aprender & Aprendizagem \\
\hline 1 & 4 & 53 \\
\hline 2 & 17 & 67 \\
\hline 3 & 63 & 152 \\
\hline 4 & 45 & 79 \\
\hline 5 & 45 & 115 \\
\hline 6 & 51 & 181 \\
\hline 7 & 228 & 234 \\
\hline 8 & 14 & 10 \\
\hline 9 & 9 & 50 \\
\hline 10 & 52 & 45 \\
\hline 11 & 8 & 27 \\
\hline 12 & 13 & 41 \\
\hline 13 & 25 & 34 \\
\hline 14 & 23 & 125 \\
\hline 15 & 38 & 29 \\
\hline 16 & 14 & 26 \\
\hline 17 & 260 & 102 \\
\hline 18 & 55 & 147 \\
\hline
\end{tabular}

É interessante perceber que em todas as teses investigadas, ora aparece a palavra aprender, ora aprendizagem. Por vezes, aprender se sobressai em relação à aprendizagem, como nas teses $8,10,15,17$. Contudo, na maioria, há uma 
incidência maior da palavra aprendizagem. Somente na tese 7 , ambas as palavras foram excessivamente usadas, quase que igualmente em relação à quantidade de vezes. Vale ressaltar que essa tabela apenas nos mostra as variaçóes quantitativas, mas nada dizem sobre as diferenças conceituais ou mesmo sobre as variaçóes discursivas.

Para tal fim, uma leitura atenta de cada tese tornou-se necessária, reunindo as informaçóes que constituíram o quadro D: autores utilizados como referencial teórico nos momentos onde são citadas as palavras "aprender" e/ou "aprendizagem", nível ou categoria de ensino no qual foi realizada a pesquisa e os conceitos e/ou teorizaçóes abordados ao longo das teses.

\section{Quadro D}

\begin{tabular}{|c|c|c|c|}
\hline $\mathbf{N}^{\circ}$ & Autores & $\begin{array}{l}\text { Nível ou categoria } \\
\text { de ensino }\end{array}$ & Conceitos/Teorizaçóes \\
\hline 1 & $\begin{array}{l}\text { Demetrio Delizoicov; Paulo Freire; Alice } \\
\text { Pierson; Henry Giroux; }\end{array}$ & $\begin{array}{l}\text { Ciências na } \\
\text { educaçáo básica }\end{array}$ & Três Momentos Pedagógicos \\
\hline 2 & $\begin{array}{l}\text { Demetrio Delizoicov; Henry Giroux; James } \\
\text { Prescott Joule }\end{array}$ & $\begin{array}{l}\text { Formação de } \\
\text { professores } \\
\text { universitários de } \\
\text { Física }\end{array}$ & $\begin{array}{l}\text { Estudo Histórico } \\
\text { Sociocultural dos Trabalhos } \\
\text { de James Prescott Joule }\end{array}$ \\
\hline 3 & $\begin{array}{l}\text { Paulo Freire; Maria do Carmo Galiazzi; } \\
\text { Carl Rogers; Rachel Léa Rosenberg; Miguel } \\
\text { A. Zabalza; Marcos T. Masetto; Juan Díaz } \\
\text { Bordenave; Ricardo Shoiti Komatsu; Nilce } \\
\text { Maria Silva Campos Costa; Antônio Carlos } \\
\text { Gil; }\end{array}$ & Educação médica & $\begin{array}{l}\text { Aprendizagem Baseada em } \\
\text { Problemas (ABP); Perfil } \\
\text { Humanista de Carl Rogers; }\end{array}$ \\
\hline 4 & $\begin{array}{l}\text { Humberto Maturana; Francisco Varela; } \\
\text { Mauricio Pietrocolo; Jean Piaget; Maria do } \\
\text { Carmo Galiazzi; }\end{array}$ & $\begin{array}{l}\text { Formação de } \\
\text { professores da } \\
\text { área das ciências e } \\
\text { exatas }\end{array}$ & $\begin{array}{l}\text { Objetos Virtuais de } \\
\text { Aprendizagem; Biologia do } \\
\text { Conhecer; Tecnologias da } \\
\text { Informação e Comunicação } \\
\text { (TIC) }\end{array}$ \\
\hline 5 & $\begin{array}{l}\text { Humberto Maturana; Pierre Lévy; Lee } \\
\text { Shulman; Maurice Tardif; Ana Maria } \\
\text { Cavalcanti Lefèvre; Fernando Lefèvre; } \\
\text { Marcos Tarciso Masetto; }\end{array}$ & $\begin{array}{l}\text { Educação a } \\
\text { distância de cursos } \\
\text { técnicos com } \\
\text { professores tutores. }\end{array}$ & $\begin{array}{l}\text { Ambiente Virtual de } \\
\text { Aprendizagem (AVA); } \\
\text { Discurso do Sujeito Coletivo } \\
\text { (DSC); Cultura Em Redes } \\
\text { De Conversaçáo; Inteligência } \\
\text { Coletiva; Conhecimento } \\
\text { Pedagógico Do Conteúdo; }\end{array}$ \\
\hline 6 & $\begin{array}{l}\text { Paulo Freire; Jean Piaget; David Ausubel; } \\
\text { Yves Bertrand; Cipriano Carlos Luckesi; }\end{array}$ & Educação médica & $\begin{array}{l}\text { Aprendizagem Baseada em } \\
\text { Problemas (ABP) }\end{array}$ \\
\hline
\end{tabular}




\begin{tabular}{|c|c|c|c|}
\hline $\mathbf{N}^{\circ}$ & Autores & $\begin{array}{l}\text { Nível ou categoria } \\
\text { de ensino }\end{array}$ & Conceitos/Teorizaçóes \\
\hline 7 & $\begin{array}{l}\text { Humberto Maturana; Francisco Varela; } \\
\text { Ximena Dávila; Maria Cecília de Souza } \\
\text { Minayo; Mário Osório Marques; Saturnino } \\
\text { de la Torre; Antoni Zabala; César Coll } \\
\text { Salvador; Sima Nisis de Rezepka; Juan } \\
\text { Ignácio Pozo; Miguel Angel Gomez Crespo; } \\
\text { Ana Maria Cavalcanti Lefèvre; Fernando } \\
\text { Lefèvre; }\end{array}$ & $\begin{array}{l}7^{\circ} \text { e } 8^{\circ} \text { ano da } \\
\text { Educação Básica }\end{array}$ & $\begin{array}{l}\text { Ambientes virtuais de } \\
\text { Aprendizagem; Discurso do } \\
\text { Sujeito Coletivo (DSC); }\end{array}$ \\
\hline 8 & Maria do Carmo Galiazzi; Roque Moraes; & Educação química & $\begin{array}{l}\text { Hermenêutica; Tradição de } \\
\text { linguagem; }\end{array}$ \\
\hline 9 & $\begin{array}{l}\text { Nancy J. Nersessian; Cleci Werner da Rosa; } \\
\text { Clermont Gauthier; Mario Richard; Steve } \\
\text { Bissonnette; Richard Solomon; }\end{array}$ & $\begin{array}{l}\text { Física no ensino } \\
\text { médio politécnico }\end{array}$ & $\begin{array}{l}\text { Método Cognitivo-histórico } \\
\text { (MCH); Ensino Explícito; } \\
\text { Solomon Four Group Design, }\end{array}$ \\
\hline 10 & $\begin{array}{l}\text { Humberto Maturana; Michael G. Moore; } \\
\text { Greg Kearsley; Ana Maria Cavalcanti Lefêvre; } \\
\text { Fernando Lefevre; }\end{array}$ & $\begin{array}{l}\text { Gestão do ensino } \\
\text { superior }\end{array}$ & $\begin{array}{l}\text { Ensino mediado por } \\
\text { tecnologias digitais da } \\
\text { informaçáo e comunicação; } \\
\text { Discurso do sujeito coletivo } \\
\text { (DSC); }\end{array}$ \\
\hline 11 & $\begin{array}{l}\text { Maria do Carmo Galiazzi; Juares Da Silva } \\
\text { Thiesen; Edgar Morin; Roque Moraes; }\end{array}$ & $\begin{array}{l}\text { Formação de } \\
\text { professores, área } \\
\text { das ciências da } \\
\text { natureza }\end{array}$ & Hermenêutica \\
\hline 12 & $\begin{array}{l}\text { André Chervel; Simone Grellet Pereira } \\
\text { Fernandes; J. Gimeno Sacristán; Ángel I. } \\
\text { Pérez Gómez; David Layton. }\end{array}$ & $\begin{array}{l}\text { Disciplina de física } \\
\text { no ensino médio }\end{array}$ & Teoria de David Layton. \\
\hline 13 & $\begin{array}{l}\text { Paulo Freire; Maria do Carmo Galiazzi; Joáo } \\
\text { Alberto Steffen Munsberg; Roque Moraes; }\end{array}$ & $\begin{array}{l}\text { Ensino médio } \\
\text { politécnico / } \\
\text { ciências exatas e } \\
\text { natureza }\end{array}$ & Fenomenologia-hermenêutica \\
\hline 14 & $\begin{array}{l}\text { Jean Piaget; Maria Luiza Rheingantz Becker; } \\
\text { Jean Marie Dolle; }\end{array}$ & $\begin{array}{l}\text { Alfabetização / } \\
\text { matemática }\end{array}$ & $\begin{array}{l}\text { Epistemologia Genética } \\
\text { piagetiana }\end{array}$ \\
\hline 15 & $\begin{array}{l}\text { Humberto Maturana; Francisco Varela; } \\
\text { Ximena Dávila; }\end{array}$ & $\begin{array}{l}\text { Formaçáo de } \\
\text { professores da área } \\
\text { de exatas }\end{array}$ & $\begin{array}{l}\text { Biologia do Conhecer; } \\
\text { cartografia; }\end{array}$ \\
\hline 16 & $\begin{array}{l}\text { Humberto Maturana; Miguel A. Zabalza; } \\
\text { Antoni Zabala; Ana Maria Cavalcanti } \\
\text { Lefèvre; Fernando Lefèvre; }\end{array}$ & $\begin{array}{l}\text { Formação de } \\
\text { professores da área } \\
\text { da biologia }\end{array}$ & $\begin{array}{l}\text { Laboratório de Ensino e } \\
\text { Prática Docente - } \\
\text { LEPD; Discurso do Sujeito } \\
\text { Coletivo (DSC); }\end{array}$ \\
\hline 17 & $\begin{array}{l}\text { Humberto Maturana; Francisco Varela; } \\
\text { Fabiane Barreto Vavassori; André Luís Alice } \\
\text { Raabe; Ximena Dávila; Marcelo Braga; Rosa } \\
\text { Monteiro Paula; }\end{array}$ & $\begin{array}{l}\text { Educação } \\
\text { matemática no } \\
\text { ensino superior }\end{array}$ & $\begin{array}{l}\text { Biologia do Conhecer de } \\
\text { Humberto Maturana e } \\
\text { Francisco Varela; Ambiente } \\
\text { Virtual de Aprendizagem } \\
\text { (AVA); }\end{array}$ \\
\hline
\end{tabular}




\begin{tabular}{|l|l|l|l|}
\hline $\mathbf{N}^{\circ}$ & Autores & $\begin{array}{l}\text { Nível ou categoria } \\
\text { de ensino }\end{array}$ & Conceitos/Teorizaçóes \\
\hline 18 & $\begin{array}{l}\text { Maria do Carmo Galiazzi; Lev Vygotsky; } \\
\text { Eder Pires de Camargo; Roque Moraes; Van } \\
\text { Hiele. }\end{array}$ & $\begin{array}{l}\text { Formação de } \\
\text { professores da } \\
\text { áea de exatas / } \\
\text { inclusão de alunos } \\
\text { cegos }\end{array}$ & $\begin{array}{l}\text { Hermenêutica; Teoria de Van } \\
\text { Hiele; Objetos virtuais de } \\
\text { Aprendizagem; }\end{array}$ \\
\hline
\end{tabular}

\section{Das análises arquivísticas}

Os arquivamentos realizados a partir das 18 teses de doutorado da área de ensino, do período de 2010 a 2019 nos permitiram algumas análises: em relação à formação inicial dos autores das teses, embora haja uma diversidade de áreas de formação, a grande parte é oriunda da área de Ciências Exatas, ou seja, de 18 autores, 14 são da referida área. Isso possivelmente se explica, pois a área de ensino, como já mencionado, inseriu-se na Grande Área Multidisciplinar, agregando a Área de Ensino de Ciências e Matemática, de modo que ainda percebe-se uma incidência bastante grande de pesquisadores das áreas de Ciências Exatas realizando seus estudos de doutorado na área de Ensino. Essa incidência da área de Ciências Exatas também fica evidente na atuação profissional dos autores das teses pesquisadas, já que grande parte destes profissionais atuam em disciplinas de educação básica ou Ensino Superior, voltadas para essa área. Um outro ponto a destacar na análise feita são as abordagens teóricas e conceituais das teses e nesse sentido percebe-se uma miscigenação de abordagens que sustentam as noçóes de aprender/aprendizagem, distribuídas em programas de ensino. Tal percepção pode novamente ser analisada a partir da constatação que o Ensino é uma área multidisciplinar, a qual, conforme o Documento de Área Ensino, do Ministério da Educação (2016), assume “[...] a situação da Educação Básica no país, bem como os desafios para formação continuada de docentes universitários, e de professores na educação básica, técnica e superior, e educadores em geral" (2016, p.10). Desse modo, com relação aos conceitos e/ou teorizaçóes utilizados pelas teses: 02 operaram com Objetos virtuais de aprendizagem; outras 03, com os Ambientes virtuais de aprendizagem (AVA), 02 com Tecnologias de informação e comunicação (TICs). Assim, das 18 teses analisadas, 07 delas relacionam o aprender/aprendizagem com recursos tecnológicos. Ainda pode se destacar que 02 abordam a Aprendizagem baseada em problemas (ABP); 03 estáo relacionadas com a Biologia do Conhecer de Maturana e Varela e 04 com a hermenêutica. As outras 04 situam-se entre a Epistemologia genética de Piaget, Estudo Histórico Sociocultural; Teoria de David Layton; Laboratório de Ensino e Prática Docente.

Também observa-se que 15 das 18 teses, provém da Universidade Federal do Rio Grande (FURG), sendo 8 do Programa Educação em Ciências Química da Vida e Saúde - Processos de Ensino e Aprendizagem na Escola, na Universidade e no Laboratório de Pesquisa; 7 são do Programa Educação em Ciências Química da Vida e Saúde - As Tecnologias Educativas no Processo de Aprendizagem. As demais teses, sáo vinculadas à Universidade Federal de Santa Maria (UFSM), Universidade 
Federal de Santa Catarina (UFSC) e Universidade Estadual Paulista (UNESP). Ainda aqui, poderíamos afirmar que as teses que estão operando com as noçóes de aprender/aprendizagem na área de Ensino, em sua grande maioria, sáo oriundas de duas linhas de pesquisa do mesmo Programa, voltado para Educação em Ciências Químicas. Com efeito, essas investigaçóes tomam o aprender/aprendizagem a partir de uma perspectiva mais cognitivista, utilizando na grande maioria, autores como Jean Piaget, Lev Vygotsky, David Ausubel, mas também outros autores das teorizaçóes críticas como Paulo Freire, Miguel Zabalza, Maurice Tardif, J. Gimeno Sacristán, entre outros. No entanto, alguns autores que apresentam uma perspectiva mais contemporânea ou complexa, tais como Humberto Maturana, Francisco Varela, Edgar Morin, Pierre Lévy, para citar apenas os mais conhecidos, também aparecem em algumas das teses do Programa citado. O que é possível perceber, é que nenhuma das 18 teses faz mençáo a uma perspectiva do aprender no sentido deleuzeano e mesmo que muitas delas abordem a palavra aprender, é possível compreender que, provavelmente, estejam usando aprender e aprendizagem com o mesmo significado.

Em relação ao ano da defesa, existe uma concentração de teses defendidas no ano de 2017 (8 de 18). As demais, se dividem em 03 teses em 2014; 02 teses em 2013, 02 teses em 2016, 01 tese no ano de 2010, 01 no ano de 2012 e 01 em 2019. Dos demais anos que estáo no intervalo de tempo da presente pesquisa $(2011,2015$ e 2018), não houve nenhuma tese que se enquadrasse na temática.

\section{In-conclusóes}

Quantas noções de aprender/aprendizagem aparecem na pesquisa educacional? E nas práticas pedagógicas? Há muitas diferenças no que diz respeito aos entendimentos, representaçôes, discursividades e práticas pedagógicas que abordam as questóes do aprender e/ou da aprendizagem no campo educacional, que vão desde uma perspectiva platônica até conceituações mais contemporâneas, tal como o aprender proposto por Gilles Deleuze ou outros como Gert Biesta, Virginia Kastrup, entre tantos.

Quando se trata de operar com um arquivo e, nesse caso, um arquivo composto de teses de doutorado, menos interessa o sujeito da enunciação, mas aquilo que da própria discursividade emerge. Mais do que isso, interessa problematizar o que mais pode ser dito, atualizado, conjugado e, inevitavelmente, dispersado, pois, como relembra Foucault (2001, p. 49), "o discurso nada mais é do que a reverberaçáo de uma verdade nascendo diante de seus próprios olhos".

Olhar para as teses de doutorado que abordam as noçôes de aprender/ aprendizagem como objeto de estudo, entre o período de 2010 - 2019, da área de Ensino, consistiram no norte deste trabalho. Os arquivamentos efetuados e as análises realizadas foram uma tentativa - sem nenhuma pretensão de resultados conclusivos - de mostrar as diferentes formas como as noçóes de aprender e de aprendizagem estáo sendo pensadas e operadas em teses na área de ensino. Os achados nos mostraram que há diferentes abordagens, como já mencionado, 
mas também mostraram que a área de Ensino ainda traz fortemente pesquisas e pesquisadores, oriundos do campo das Ciências Exatas. Como em todo extrato enunciativo há sempre um lugar de enunciação, um lugar daquele que fala e, nesse sentido, as discursividades dos pesquisadores investigados carregam consigo o seu lugar de formaçáo e consequentemente um determinado modo de ver o campo educacional, assim como, as resultantes conceituaçóes e teorizaçôes.

\section{Referências}

BRASIL. Ministério da Educação. Coordenação de Aperfeiçoamento de Pessoal de Nível Superior. Documento de Área Ensino. Brasília, 2016. Disponível em: https://pos. cepae.ufg.br/up/480/o/DOCUMENTO_DE_AREA_ENSINO2016final.pdfAcesso em 07/07/2019.

DELEUZE, Gilles. Proust e os signos. Trad. Antônio Carlos Piquet e Roberto Machado. Rio de Janeiro: Forense Universitária, 2003.

DELEUZE, Gilles. Diferença e repetiçáo. Trad. Luiz Orlandi e Roberto Machado. Rio de Janeiro: Graal, 2006.

GALLO, Silvio. As múltiplas dimensóes do aprender. In: Congresso de Educação Básica - COEB: aprendizagem e currículo. Anais do... Florianópolis: COEB, 2012.

Disponível em: http://www.pmf.sc.gov.br/arquivos/arquivos/pdf/13_02_2012_10.54.50. a0ac3b8a140676ef8ae0dbf32e662762.pdf Acesso em: 20/05/2018

FOUCAULT, Michel. Michel Foucault explica seu último livro. In: FOUCAULT, Michel. Arqueologia das ciências e história dos sistemas de pensamento. Trad. Elisa Monteiro. (Col. Ditos e escritos, II). Rio de Janeiro: Forense Universitária, 2000, p. 145-152.

FOUCAULT, Michel. A ordem do discurso. Trad. Laura Fraga de Almeida Sampaio. São Paulo: Ediçóes Loyola, 2001.

FOUCAULT, Michel. A hermenêutica do sujeito. Trad. Márcio Alves da Fonseca e Salma Tannus Muchail.São Paulo: Martins Fontes, 2004.

FOUCAULT, Michel. A arqueologia do saber. Trad. Luiz Felipe Baeta Neves. Rio de Janeiro: Forense Universitária, 2008.

LARROSA, Jorge. P de Professor. São Carlos: Pedro \& João Editores, 2018.

MASSCHELEIN, Jan; SIMONS, Maarten. Em defesa da escola: uma questão pública. Trad. Cristina Antunes. Belo Horizonte: Autêntica, 2018.

NIETZSCHE, Friedrich. Escritos sobre Educaçáo. Traduçáo de Noéli Correia de Melo Sobrinho. Rio de Janeiro: Ed. PUC-Rio; São Paulo: Loyola, 2004.

SPINOZA, Baruch. Ética. Trad. e Notas Tomaz Tadeu. Belo Horizonte: Autêntica, 2007. 